\title{
(In)certeza jurídica em tempos de pandemia: desafios ao Direito
}

https://doi.org/10.21814/uminho.ed.25.2

\section{Maria Clara Calheiros}

Maria Clara Calheiros (ORCID: 0000-0001-9324-5813) é Professora Catedrática da Escola de Direito da Universidade do Minho. É licenciada e mestre em Direito pela Escola de Direito da Universidade do Minho e Doutora em Direito pela Faculdade de Direito da Universidade de Santiago de Compostela. É autora de publicações nas áreas de Filosofia do Direito, História do Pensamento Jurídico, Teoria do Direito, Teoria da Prova, Metodologia do Direito. Presentemente, dirige o grupo de investigação «Laboratório da Justiça» (JusLab) do Centro de Investigação JusGov. 


\section{INTRODUÇÃO}

O mote das reflexões que partilho aqui com o leitor é a pandemia que se abateu sobre todos nós no ano 2020. Eu, como todos os demais, tenho a percepção de estar confrontada com uma situação nova, com contornos, consequências e alcance desconhecidos. No entanto, na realidade, trata-se de uma situação que se tem repetido ciclicamente na história da Humanidade e, nessa medida, é "nova" apenas no sentido em que, no nosso tempo de vida e no tempo de vida dos nossos pais e avós, nunca foi vivida, nem nos foi relatada, em discurso directo. De facto, se pesquisarmos, ainda que muito superficialmente, facilmente encontramos registos históricos, bem próximos no tempo, a propósito da pandemia que ficou conhecida mundialmente como "gripe espanhola". De resto, porque se trata de um evento não tão distante assim, temos abundantes registos fotográficos que parecem ser uma versão a preto e branco das imagens que inundaram os nossos televisores e os écrans dos telemóveis e computadores: homens e mulheres de máscaras, hospitais de campanha, cemitérios esventrados pelas incontáveis covas abertas para a inumação dos mortos, etc.

Dito isto, e continuando a usar o argumento de estarmos a viver um tempo que parece novo, mas não o é, descarto desde início a tese, a que muitos prontamente aderiram, de que esta é uma situação transformadora e que tudo será diferente a partir de agora. Com efeito, não faltaram opinióes, recetíveis para a vox populi, mas também com origem nas elites mais ou menos intelectuais, a vaticinar alterações radicais no nosso modo de vida, muitas vezes associadas a uma visão catártica da pandemia, como se por esta via o mundo estivesse a viver acontecimentos predestinados, com a finalidade salvífica de nos guiar para outro patamar de "consciência" (expressão favorita dos gurus que pululam as redes sociais), conduzidos que seríamos, enfim, a uma reaproximação das famílias, a uma reaprendizagem dos valores, a um reaprendido respeito pela natureza e pelo "outro". Confesso que talvez a minha deformação profissional, como jurista, me tenha tornado demasiado cínica e por isso tenha dificuldade em acreditar que a Humanidade consegue aprender liçôes e não repetir, uma e outra vez, erros do passado. Talvez, também por isso, continuo a gostar particularmente da frase de Lampedusa, em Il gatopardo: "Se vogliamo che tutto rimanga come è, bisogna che tutto cambi." Também nesta pandemia vejo as 
mudanças sobretudo como ajustamentos necessários para que, no essencial, tudo permaneça inalterado.

O que me interessa nesta pandemia, desde a minha perspectiva como membro da academia e como jurista, não é, portanto, o seu potencial transformador (do qual desacredito, como acabei de dizer), mas antes o facto de constituir um evento que permite, justamente, na minha opinião, explorar e explicar os dilemas aporéticos com que o Direito vem lidando desde sempre. Refiro-me, em particular, à questão da previsibilidade que é pedida ao Direito pela sociedade, e que encontra no feixe concetual das ciências jurídicas várias expressóes, entre elas a certeza e segurança jurídicas. Por isso mesmo, nas linhas que se seguem, vou convidar o leitor a revisitar comigo o percurso histórico mais próximo que erigiu a certeza jurídica como uma finalidade do Direito e procurarei demonstrar, recorrendo à análise da pandemia, a dificuldade/impossibilidade do Direito nos conduzir até essa terra prometida.

\section{A RELEVÂNCIA DA CERTEZA PARA O DIREITO: PERCURSOS HISTÓ- RICOS EM TORNO DA QUESTÃO DA IMPREVISIBILIDADE}

A certeza é importante na nossa vida - mesmo que no tempo atual se diga que não podemos ter nada por certo (ou garantido) o que é a mesma coisa. Esta certeza de que falo é aquela que respeita à nossa necessidade de fazermos constantes juízos de prognose com vista a podermos guiar a nossa acção, a podermos tomar decisóes. De um modo geral, o ser humano procura sempre, em todos os domínios da vida, compreender com antecipação as consequências previsíveis das nossas acções ou da falta delas. Poderíamos aqui oferecer incontáveis exemplos, desde as previsóes meteorológicas até às previsões económicas, passando (aqui só pelo carácter anedótico) pelas previsóes astrológicas, todas avidamente consumidas por distintos grupos. Por certo, uma das maiores consequências disruptivas da pandemia foi, seguramente, ter interrompido ou suspendido os nossos horizontes de previsibilidade. Subitamente, todos deixamos de ter a certeza de poder marcar as costumeiras férias, ou fazer coisas tão triviais como festejar um aniversário. 
A demanda por certeza é algo que está, e esteve, presente na evolução histórica do direito e tem múltiplas manifestaçóes. Sem compreendermos este desejo ou expetativa humana, perderemos a possibilidade de compreendermos o núcleo da própria evolução histórica do direito e o desenho da ciência jurídica moderna. A certeza é ínsita ao acto de julgar e às nossas expetativas quanto a ele, como bem soube assinalar Ricouer. Diz-nos este autor: "importa sublinhar a necessidade social que se atribui a esta finalidade, que denominámos curta, e que consiste na interrupção da incerteza. Nos estritos limites do processo, o acto de julgar aparece na fase final de um drama com várias personagens [...] Além do mais, este acto terminal aparece como o encerramento de um processo aleatório; a este respeito estamos próximos da conduta adoptada numa partida de xadrez: as regras do jogo são conhecidas, mas ignora-se, em cada jogada, como é que a parte será conduzida ao seu objectivo."

Também na literatura encontramos uma via para compreender o lugar importante que ocupa a certeza no Direito. Na obra genial de Kafka, O Processo, Josef K. descobre-se preso a um processo cuja natureza e contornos nunca lhe são revelados e, por isso, ele deixa de ser pura e simplesmente livre, passando a viver dominado pelo processo. Durante toda a obra somos confrontados com a perplexidade e angústia do protagonista submetido a um processo judicial de que nada sabe, fonte contínua da tortura a que a personagem é submetida. De tal modo que, a dado ponto, ao ser impedido de ler os livros do juiz, expressa a sua angústia com particular clareza dizendo:

"Faz parte desse género de justiça que uma pessoa seja não só condenada inocentemente, mas também desconhecendo a lei.” (p.37)

O que me importa aqui é sublinhar o modo como o personagem nos indica, nestas palavras, como considera que a injustiça da sua situação não advém apenas de estar convicto de que nada fizera de mal, mas também de maneira acrescida por não lhe ser dado sequer conhecer, ao certo, a sua posição perante a lei. Poder ser, enfim, o juiz de si próprio e das suas acçôes, poder fazer o seu juízo de prognose sobre o desfecho possível que o aguardava: isso era, em grande medida aquilo por que ansiava e que, sendo-lhe negado, o angustiava.

1 Ricouer, P. (1997). O justo ou a essência da justiça, Lisboa: Piaget: 165. 
Voltando o olhar para o percurso histórico do Direito, podemos marcar como referente da centralidade que a questão da certeza assumirá no mundo jurídico o advento do Humanismo. No seu contexto, haveria de criticar-se a confusão normativa característica do direito medieval, o dúbio rigor filológico e lógico em que, por então, assentara o labor interpretativo, cujos resultados parecem incompatíveis com a certeza que as novas sociedades europeias começam a reclamar ao Direito. $\mathrm{O}$ antropocentrismo da época alia-se à paralela renovação das formas políticas para permitir a substituição do paradigma da "descoberta" do direito (própria das formas jurídicas medievais) pelo da criação da "lei”. Daqui derivam duas consequências importantes: a transformação do direito num instrumento da vontade política soberana e a conversão do jurista - anteriormente um detentor de auctoritas social indisputável - no exegeta da lei, o cultor do método, que assegurará, pelo rigor interpretativo, a já mencionada certeza do Direito.

A Aufklärung dará o golpe final na conceção do Direito como descoberta e na inerente autoridade de criação do direito associada aos juristas. $\mathrm{O}$ conceito de direito natural jusracionalista nada mais é do que uma tentativa de fixar os princípios de uma legislação ideal, que se pudesse concretizar, hermeneuticamente, através de procedimentos lógico-formais. Em matéria de método, o cânone que se pretende seguir é o estabelecido pelas ciências da natureza, cuja fundamentação filosófica resulta do proposto por Descartes.

Pensa-se que a lei contém já a solução do caso concreto, apenas cabendo ao jurista a tarefa de encontrar a lei aplicável e realizar a operação lógica de subsunção, retirando daí uma conclusão necessária. Esta é também uma época em que se sublinha a necessidade de que o Direito ofereça segurança e certeza jurídica, o que haverá de realizar-se, em grande medida, através do desenvolvimento do conceito de direito como Sistema, assente nos postulados da coerência e da plenitude dos ordenamentos jurídicos. Eis, pois, a metodologia jurídica moderna, de cariz lógico-dedutivo ${ }^{2}$.

\footnotetext{
2 Uma análise minuciosa do processo histórico que aqui sumariamos pode ser encontrada em Calvo Garcia, Los fundamentos del método jurídico: una revisión crítica: 44-62.
} 
Assim, na transição para o séc. XIX, a interpretação já se tinha convertido numa tarefa assente, essencialmente, sobre a ideia de sistematicidade ${ }^{3}$. É esta última que permite: entender corretamente o sentido da lei, superar as dificuldades de interpretação e completar o próprio ordenamento jurídico. A ciência do Direito é uma "Ciência da Legislação"

Este novo Direito não pode ser sustentado num sistema de autoridades, como até então. As fontes da sua legitimação hão-de agora, em consonância com as mudanças operadas na estrutura político-social, encontrar-se nas formas de positivação desse mesmo Direito. Isto mesmo há-de conduzir, inevitavelmente, ao processo de progressiva estatização do Direito, para o que muito contribui o movimento da codificação. Doravante, o Direito expande-se, sistematiza-se e complexifica-se, o que exigirá o surgimento de uma nova casta de juristas profissionais e especializados. E é este novo direito estatal, sistemático, apoiado por um corpo técnico de juristas exegetas, que há-de concretizar a certeza jurídica tão desejada.

O novo direito codificado materializa os ideais de plenitude, coerência, sistematicidade dos ordenamentos jurídicos, e pretende ser o meio de garantia efectiva da segurança jurídica. Muitos destes postulados, característicos do formalismo jurídico,

\footnotetext{
3 Consideramos, pois, que a ideia de sistema é um produto anterior, consolidado com os "excessos da razão" de que fala Foucault, ao interpretar com um sentido crítico o opúsculo de Kant, Was ist Aufklärung?, interrogando-se sobre os excessos de poder, incompreensivelmente justificados pela "razão". Cf. Foucault, M. (2006). Sobre la Ilustración, 2aed., Madrid: Tecnos: 15.

4 Acompanhamos, pois, neste ponto Barbas Homem (2003) quando afirma: "A crença segundo a qual as leis, em si mesmas consideradas, constituem o fundamento de um certo tipo de conhecimento científico expóe-se na formulação conceptual da ciência da legislação. Esta nova visão das coisas abre caminho para uma concepção do direito como ciência autónoma das restantes disciplinas científicas e, em primeiro lugar, da Teologia. Esta pretensão da construção científica do direito não é, portanto, o resultado do positivismo oitocentista, mas o resultado da reflexão da ilustração acerca das ciências, em geral, e da ciência do direito, em particular." Judex Perfectus. Função Jurisdicional e estatuto judicial em Portugal - 1640-1820, Coimbra: Almedina: 393. Em sentido contrário, defendendo a radicação originária do conceito de "ciência do direito" em oitocentos, Castanheira Neves, Questão de facto - questão de Direito, op. cit.: 870. Sobre o impacto desta visão do Direito como Ciência na educação jurídica vd. ainda Barbas Homem, op. cit.: 379 e ss, em particular página 435, sobre a conexão entre o pensamento setecentista e a emergência de uma nova disciplina de interpretação e aplicação da lei, de hermenêutica.
} 
acabam por ganhar dignidade de princípios constitucionais, a marcar doravante o pensamento jurídico, sobretudo a partir da segunda metade do séc. XIX ${ }^{5}$.

A confiança no poder criador da letra escrita ${ }^{6}$ leva os revolucionários de 1789 a plasmar, por escrito, os direitos do Homem, de modo a que estes se tornem reais e efetivos, numa demonstração da fé que depositavam em que tal, só por si, bastasse para os concretizar, como que por mero efeito da declaração. $O$ grande inspirador do ideário revolucionário, Rousseau, tinha-nos apresentado a ideia de que a lei, enquanto expressão da vontade geral, caracterizada pela generalidade e abstração dos seus preceitos, seria doravante o "mágico" instrumento 7 capaz de assegurar a quadratura do círculo: tornar-nos a todos livres no momento em que - e por que - nos prendemos uns aos outros pelas suas grilhetas.

Desde os finais do século XIX e durante todo o século XX esta Ciência Jurídica moderna, essencial à confiança social na existência de uma certeza, de uma previsibilidade que o Direito nos podia oferecer, foi sendo questionada e desconstruída. A fragilidade das suas fundaçôes foi exposta vezes sem conta, e a busca da certeza jurídica transformouse na pedra que um Sísifo jurista rola continuamente montanha acima.

A possibilidade de o Direito nos garantir certeza jurídica foi colocada em causa por diversas vias, com particular destaque para a crise da própria lei e a questão da (im)previsibilidade do sentido das decisóes judiciais de aplicação do direito.

\footnotetext{
5 Cf. Calvo Garcia (1994). Los fundamentos del método jurídico: una revisión crítica, Madrid: Tecnos: 67 e ss. $\mathrm{Na}$ opinião deste autor, que seguimos, existe uma forte interligação entre os postulados referidos e muitos dos princípios basilares em que assentam os Estados constitucionais modernos. Por exemplo, a plenitude do ordenamento jurídico parece claramente derivar da primazia da lei enquanto fonte de direito e, ainda, do próprio princípio de separação de poderes. Portanto, não se trata simplesmente de algo que decorre do desejo social de obter segurança e certeza jurídica, ou de uma vontade de absorção do direito pelo Estado: é algo mais profundo que parte do facto de se assumir agora, como única forma de legitimidade, da legalidade. Paralelamente, o princípio da separação de poderes aparece estreitamente associado à defesa da necessidade de uma interpretação literal da lei como única via para garantir que o juiz não invade a esfera legislativa. No campo mais específico do Direito Penal, em conexão com estas ideias e princípios, Beccaria (1738-1794) há-de preconizar uma aplicação estrita do silogismo judiciário, sobre uma base metodológica lógico-dedutiva.
}

6 Ibidem.

7 A expressão é de Garcia de Enterria (2000). Justicia y seguridad en un mundo de leyes desbocadas,Madrid: Civitas: 27. 
No entanto, a certeza e segurança jurídica permanece como uma finalidade de que o Direito não pode prescindir e é uma derivação do próprio princípio do Estado de Direito Democrático, no caso português, consagrado constitucionalmente, no artigo 2o da nossa lei fundamental.

$\mathrm{Na}$ verdade, a certeza jurídica é de tal modo importante que, em múltiplas ocasiôes prevalece sobre as exigências que derivariam de outras finalidades do Direito. Radbruch $^{8}$ fala da existência de uma relação de tensão entre justiça e segurança. $\mathrm{O}$ autor dá vários exemplos desta tensão e dos diferentes níveis que a caracteriza. No entanto, considera que não é possível, nem desejável, para o direito, eliminar esta tensão:

"A nossa conclusão será, pois, esta: os três lados da ideia de direito - Justiça, Fim e Segurança - dominam a este ao mesmo tempo, sob qualquer dos aspectos da vida jurídica que se considere, embora entre eles por vezes surjam e não possam deixar de surgir contradições. Há por vezes épocas históricas que pretendem atribuir maior importância a um só destes lados do que aos outros”".

De tudo aqui escrito resulta que, ainda que com múltiplas dificuldades de concretização, esta associação do Direito a uma resposta a uma necessidade de previsibilidade e certeza, no plano social, surgida no fio da história que procuramos aqui, brevemente, desenrolar, continua bem presente no que respeita às nossas expectativas sobre o Direito. Mas não se tratará apenas, porventura, de uma ficção?

\section{A INCERTEZA DA VIDA E A IMPREVISIBILIDADE DOS REMÉDIOS: O DIREITO DA PANDEMIA}

A incerteza faz parte da vida, mas nós tendemos a esquecer isso: fazemos muitos planos, definimos objectivos e metas e vivemos muitas vezes o futuro mais do que presente. E uma e outra vez, e outra vez ainda, somos lembrados de que, afinal, apenas o dia de hoje nos pertence. Por isso...

8 Radbruch (1974). Filosofia do Direito, trad. cabral de Moncada, Coimbra: Arménio Amado ed.: 162-164.

9 Idem, ibidem. 
Eis que, em março de 2020, todos somos confrontados com a pandemia. E com ela surge a necessidade de atuar em reação à nova realidade distópica com que fomos surpreendidos. Os tempos eram de extrema incerteza, tanto mais que quase nada se sabia com grande fiabilidade sobre a doença, a forma de a prevenir ou combater. Certa era apenas a necessidade urgente de procurar, com rapidez, adoptar medidas que pudessem suster o contágio, o que implicaria uma paralisação dos países, a todos os níveis, numa experiência social desconhecida de todos.

Foi neste contexto, de calamidade global, que no dia 18 de março de 2020 foi decretado, em Portugal, o Estado de Emergência, através do Decreto do Presidente da República no 14-A/2020. Este diploma veio permitir a aplicação de medidas extraordinárias e de carácter urgente de restrição parcial de direitos e liberdades. O Estado de Emergência veio a ter sucessivas prorrogações e permitiu, durante a sua vigência, a implementação de medidas sem precedente na nossa experiência histórica pós-revolucionária e que aqui, avulsamente, mencionamos: limitação do direito de circulação no território nacional; restriçôes à liberdade contratual e ao direito de propriedade; restrição ao direito à greve e às manifestaçóes; restrições à liberdade de culto, nas suas manifestações colectivas ou de grupo. A execução das medidas, através da sua definição no plano concreto, coube ao Governo, seguindo o constitucionalmente estatuído, que também por via legislativa determinou um conjunto de medidas que alteraram radicalmente, a partir da sua entrada em vigor, o cenário de previsibilidade com que a sociedade portuguesa contava. Senão vejamos: daí derivou a especial proteção de grupos sociais de risco (os maiores de setenta anos); o confinamento domiciliar dos infetados (ou casos suspeitos) sem internamento hospitalar; a restrição da liberdade geral de circulação à necessária para satisfazer certas necessidades; o encerramento do comércio e serviços; a instituição do teletrabalho; a suspensão ou limitação dos serviços de transportes; o encerramento da fronteira terrestre, com exceções; a proibição de atracagem de certas categorias de embarcações.

Dado que o Estado de Emergência tem a sua duração limitada a 15 dias, nos termos da Constituição, mas também porque a situação ía evoluindo, também as medidas adotadas foram sendo alteradas nas sucessivas prorrogações do Estado de Emergência. De um modo geral, sem estar aqui a escalpelizar as medidas adotadas podemos dizer 
que concordamos com a avaliação daqueles que as caracterizaram como medidas com elevado grau de impacto na nossa liberdade ${ }^{10}$, fruto de uma escolha difícil entre salvar vidas ou salvar a economia. Basta lembrar os impactos no comércio e serviços, em particular na hotelaria e restauração. Mas mais do que isso, foi o sentido de normalidade da vida que ficou em suspenso: os nossos projectos de vida foram afectados a todos os níveis: alteração do modo de ensinar e de aprender; cancelamento ou adiamento de casamentos e baptizados; mudança nas formas de trabalho; perda de emprego e de rendimentos; disrupção das relaçôes familiares, com o isolamento dos avós; limitaçóes no modo de chorar os nossos mortos, etc.

Sucede, porém, que tempos de incerteza são sempre tempos de grande confusão e desorientação. De tal sorte que, em paralelo ao processo com tutela constitucional que acima descrevemos, foi-se assistindo no país a atuações de entidades públicas avulsas não respaldadas pelo Direito, a que a intervenção da Provedoria da Justiça foi pondo cobro. Cito, em particular, a atuação da Autoridade de Saúde Regional do Algarve e a Unidade de Saúde Local do Nordeste que impuseram, invocando a situação pandémica, uma quarentena profilática a todos aqueles que regressassem do estrangeiro. A Provedora de Justiça reagiu, enviando ofício à Direcção Geral de Saúde ${ }^{11}$, em 24 de março de 2020, onde expunha com meridiana clareza a falta de sustentação legal daquelas actuações.

Todavia, o caso mais grave em matéria de ingerência nas nossas liberdades e direitos ocorreu, talvez, nos Açores. Com efeito, um cidadão português, piloto de aviação residente nos Açores, viu-se confrontado à sua chegada a $S$. Miguel com a imposição de uma quarentena profilática num hotel, por determinação do Governo Regional. Efetivamente, porque a situação configurava a de uma detenção ilegal, foi apresentado um pedido de habeas corpus no Tribunal de Ponta Delgada, com a solicitação de libertação imediata, que veio a ser julgado procedente. Vale a pena descrever

10 Veja-se a caracterização realizada a este respeito, em particular sobre as medidas de polícia sanitária, de Carla Amado Gomes (2020). "Legalidade em tempos atípicos: notas sobre as medidas de polícia sanitária no âmbito da pandemia” in Revista do Ministério Público, Junho: 43-78.

11 Ofício da Provedora de Justiça disponível em http://www.provedor-jus.pt/site/public/archive/ doc/2020 $03 \quad 24$ DGS.pdf, último acesso 30.06.2020. 
aqui um pouco mais em detalhe os contornos da situação e as apreciaçôes que vieram a ser realizadas pelo Tribunal.

O referido cidadão alegou que, tendo chegado aos Açores em 10 de maio de 2020, vindo de Lisboa, num voo da TAP, fora levado, contra sua vontade, sob escolta policial, para um Hotel, onde juntamente com os passageiros do voo, teria de permanecer, confinado no quarto que lhe foi atribuído, sem poder manter contactos com outras pessoas, designadamente os seus familiares. A sua oposição, manifestada desde o primeiro momento, até porque nem tinha sintomas de doença, nem lhe foi efetuado qualquer teste, foi desconsiderada, uma vez que estaria em causa o cumprimento da Resolução 77/2020 de 23 de março, emanada pelo Governo Regional dos Açores. Os argumentos apresentados em Tribunal para sustentar a defesa da posição do Governo Regional dos Açores são curiosos, em particular o que respeita à tentativa de sustentar que não se tratava de uma privação de liberdade porque o cidadão em causa podia sempre... ir embora dos Açores, onde, no entanto, até residia.

Em face destas circunstâncias de facto, que se deram por provadas, decidiu o Tribunal pelo deferimento do pedido por considerar que se estava perante uma situação de privação da liberdade não enquadrável em qualquer das tipificaçôes legais que a legitimariam. A dado passo da decisão, conclui a juíza: “[o requerente foi] Não só instado a permanecer no quarto, como proibido de contactar pessoalmente com outras pessoas que ali o pudessem procurar - familiares, amigos ou conhecidos - ou mesmo com os demais passageiros que consigo desembarcaram e para ali foram conduzidos. Ficou sujeito a alimentar-se com as refeições que estão pré-definidas por outrem; ficou impedido de receber bens que não os de primeira necessidade vindos do exterior, designadamente roupa que, aparentemente, não é considerado bem de primeira necessidade; ficou responsável pela manutenção e limpeza do quarto e pelo tratamento da sua roupa pessoal, não lhe sendo dado acesso aos serviços de lavandaria do hotel. Dizer que perante este quadro é o direito de circulação do requerente que está limitado, é encarar de modo absolutamente redutor a realidade. O direito de circulação está limitado, porque limitada está a sua liberdade. Cremos que qualquer cidadão perante este quadro não tem dúvidas em concluir que a liberdade que o requerente tem naquela situação em pouco difere da liberdade que tem um recluso que se encontra preso num 
estabelecimento prisional. Que tem mais conforto, melhores condições, sem dúvida; maior liberdade de circulação, aí parece que a vantagem pende para o recluso." O deferimento do pedido de habeas corpus assenta no reconhecimento que o aresto faz de que o Governo Regional não tinha, face à Constituição, competência para restringir direitos, liberdades e garantias, mesmo tendo em conta os tempos excecionais em que vivemos. Esta decisão pôs termo ao confinamento de outros cidadãos, já que o Governo Regional acabou por decidir abandonar a imposição da quarentena a todos os que chegavam ao arquipélago.

Aqui chegados, importa observar que, por via de todas as medidas que foram aplicadas por lei, às alterações de vida derivadas diretamente da própria pandemia, se somaram as múltiplas alterações a que aquelas medidas deram azo. Essas alterações eram imprevisíveis para todos os cidadãos e tiveram um impacto esmagador nas suas vidas. Pense-se, por exemplo, na situação daqueles que viram os seus meios de sustento económico radicalmente cortados, num abrir e fechar de olhos. Note-se que não pretendo aqui discutir, por qualquer forma, o acerto das medidas. $\mathrm{O}$ meu ponto é outro: quero sustentar que as alterações legislativas promovidas, como meio de reacção à pandemia, são pela sua natureza necessariamente geradoras de incerteza, por imprevisíveis e frustradoras da confiança e das expetativas dos cidadãos. Por muito justificadas, necessárias e indispensáveis que sejam, é iniludível este seu carácter disruptivo. Mas afinal não deveria o Direito levar-nos a essa terra prometida da segurança e certeza jurídica?

\section{O DIREITO E A (IN)CERTEZA. CONCLUINDO}

Desde o ponto de vista que procuramos adotar aqui, nesta nossa breve reflexão, o que mais nos importa é salientar como a uma situação fática de imprevisibilidade e incerteza, o Direito é chamado a atuar, mas pela sua atuação outra imprevisibilidade é introduzida na vida social. A lei é reativa e, em tempos de extrema imprevisibilidade, é hiper reativa, como vimos pelos exemplos atrás elencados.

Desde meados do século XX, a lei converteu-se, cada vez mais, em lei-medida, isto é, tentativa de solução e reação face a problemas concretos, que por isso se multiplica e muda a cada instante. Carl Schmitt falou sobre este fenómeno que designou 
com uma formulação eloquente, que obteve notoriedade: motorisierter Gesetzgerber, o legislador motorizado.

Como se disse atrás, a lei é erigida, na revolução francesa e seguindo a inspiração rousseauniana, em manifesto da vontade geral e primeira garantia da liberdade de todos. No entanto, o séc. XX haveria de nos demonstrar, por via dos vários totalitarismos que viu nascer, que ela podia ser justamente uma "ameaça para a liberdade" parafraseando aqui o título da célebre conferência de Leibholz ${ }^{12}$. Todavia, dissolvida que foi a deriva totalitarista no ocidente, as democracias ocidentais confrontaram-nos ainda com outra crise da lei que é aquela que advém da atual e incontida inflação legislativa, à qual está inexoravelmente associada a perda de valor da própria lei, que se associa cada vez mais com jogos de interesses particulares e fugazes e cada vez menos com o ideal de expressão de uma vontade geral, como bem explica García de Enterría ${ }^{13}$.

Por outro lado, também a certeza jurídica enquanto previsibilidade das decisões judiciais (do seu sentido) entrou claramente em crise. Não temos aqui tempo de tecer nem sequer breves consideraçóes a este respeito, mas fica aqui apenas a nota de que o formalismo do método jurídico tradicional, nascido no contexto da busca de corresponder a uma necessidade de certeza jurídica acaba por ser criticado a partir de dentro do próprio positivismo jurídico.

Acontece que a velocidade a que as iniciativas do legislador se sucedem se tornou vertiginosa e converteu o ónus de conhecimento da lei pelos cidadãos numa imposição cínica, sem qualquer plausibilidade.

$\mathrm{Na}$ verdade, o que parece estar em causa é a própria sistematicidade do Direito. Acompanhamos, neste aspecto, a posição de García Enterría que apresenta a estabilidade como característica imprescindível dos sistemas jurídicos, ao lado da plenitude e da coerência. Na sua opinião, esta estabilidade teria de ser assegurada através de uma estrutura sólida de princípios gerais do direito, com assento constitucional.

12 Gerhard Leibholz (1964), tendo vivido a dura experiência do exílio e da perseguição pela sua origem judia, expõe de modo eloquente como o legislador pode converter-se numa ameaça para a nossa liberdade. El legislador como amenaza para la libertad en el moderno Estado de partidos, Revista de Estudios Politicos, № 137, set/out: 5-17.

13 Garcia de Enterría (2000) Justicia y seguridad en un mundo de leyes desbocadas, Madrid: Civitas: 47. 
Voltamos a nossa atenção, novamente, para o resumo breve que fizemos do "direito da pandemia". As várias iniciativas legislativas a que fizemos alusão têm, segundo os casos, uma preocupação de criação de certeza jurídica (ou melhor fora dizer, de limitação da incerteza) e, simultaneamente são causadoras dessa mesma incerteza. Explico-me. O Decreto presidencial que institui o Estado de Emergência assume-se, claramente, alinhado com o quadro e valores constitucionais de que já explicamos que a segurança jurídica faz parte. O decreto visa estabelecer um quadro tão claro e certo quanto possível para todas as medidas que, para sua implementação, tivessem que ser adotadas pelo Governo. Dessa forma, podemos dizer que a sua adopção constitui um esforço de prestar ainda homenagem à certeza jurídica, num quadro que para esta é particularmente exigente, pois reveste total excecionalidade.

Por outro lado, vemos como as medidas efetivamente adotadas para concretização do estado emergencial vão tendo configurações diversas, em espaços curtíssimos de tempo e acabam por gerar insegurança, incerteza e imprevisibilidade. Mais até do que atuação do governo, preocupa a atuação de outras entidades que, seguramente com as melhores das intençôes, aplicaram medidas com elevado grau de ingerência na liberdade dos cidadãos.

Termino com a referência ao caso dos Açores, por me parecer tão ilustrativo das tensões que a certeza e a segurança jurídica provocam no Direito. De um lado temos uma iniciativa do Governo Regional claramente limitadora, de um modo imprevisível, da liberdade individual; do outro temos a aplicação do quadro constitucional de referência que permite regressar ao terreno firme que o Direito nos prometeu oferecer.

Portanto, aqui chegados, há que ponderar se continua a fazer sentido pensar a certeza jurídica e, desde logo, pensá-la como fim que o Direito deve procurar realizar. Ora, apesar de todas as dificuldades e evidentes limitaçóes que o Direito enfrenta na procura de uma resposta a este antigo anseio das comunidades humanas, não o vejo menos realizável do que outros de que também não queremos prescindir, como a verdade ou a justiça. Haverá, no entanto, que pensar de modo distinto. Talvez nos possamos hoje acolher a uma noção mais relativista de certeza jurídica, seguindo Gommetz que pretende retomar a ratio originária do conceito «dada pelo seu carácter instrumental de servir como possibilidade de planificar de modo juridicamente consciente as 
próprias escolhas práticas» e, também, a capacidade de prever consequências jurídicas de factos (i.e. eventos independentes da acção humana) $)^{14}$.

A certeza jurídica revela-se por vezes uma miragem, outras uma construção inacabada, mas sempre nos parece algo de que dificilmente poderemos abdicar. Por uma simples razão: sem certeza (ou algum, mínimo, pálido que seja, vestígio dela) dificilmente seremos livres.

14 Gommetz (2012). La certeza juridica como previsibilidad, Madrid: Marcial Pons. 